\title{
Development of New Hydrogen-containing Tetrahydral Amorphous Carbon Thin Films using Cathodic Arc Plasma for Dental Implant
}

\author{
Tatsuyuki Nakatani ${ }^{1, *}$, Koutarou Shiraishi ${ }^{1}$ and Shinsuke Kunitsugu ${ }^{2}$ \\ ${ }^{1}$ Research Institue of Technology, Okayama University of Science \\ 1-1Ridai-cho, Kita-ku,Okayama 700-0005, Japan \\ ${ }^{2}$ Industrial Technology Center of Okayama Prefecture \\ 5301 Haga, Kita-ku,Okayama 701-1296, Japan \\ *E-mail:nakatani@bme.ous.ac.jp
}

Keywords: Diamond-like carbon, ta-C:H, dental implant,

\section{Introduction}

Recently, practical applications of a hydrogen-containing amorphous carbon $(\mathrm{a}-\mathrm{C}: \mathrm{H})$ films prepared by plasma chemical vapor deposition (CVD) method have been developed. Diamond-like carbon (DLC) films are currently used in medical devices as biocompatible and antithrombotic thin films.

The bone/dental implant interface is a vital factor for the clinical success of osseointegration defined as a direct structural and functional connection $[1,2]$. Titanium (Ti) has excellent physical properties and is the main material for dental and orthopedic implants as it is well-suited for easy osseointegration acquisition [3]. Modification of $\mathrm{Ti}$ surface properties and technological development are widely used to achieve a shorter period of osseointegration acquisition and successful strong osseointegration [3]. However, adhesion to the bone is insufficient and the durability of commercial dental implants is very low, necessitating fixing after approximately six months. Thus, an improvement in the surface of the dental implant material is required to achieve high durability and high bone-compatibility.

In a previous study, we reported that bone compatibility improves by increasing the hydrogen content in DLC films. Therefore, hydrogenated DLC films fabricated using the plasma CVD method and the magnetron sputtering method that enable easy doping of hydrogen have been studied as surface treatment methods for bone tailoring
[4-6]. Because a-C:H prepared by the CVD method are not sufficiently hard, low durability is a serious problem.

Therefore, the purpose of this study is to improve the durability and bone-compatibility of DLC films for use in dental implants. We first attempted to make hydrogen-containing tetrahedral amorphous carbon (ta-C:H) by cathodic arc ion-plating (CA) method using a graphite solid and a $\mathrm{CH}_{4}$ gas as a source for the DLC film; this approach has not been reported yet. Second, we investigated the $\mathrm{CH}_{4}$ gas flow ratio dependence of the current-voltage characteristics during the ta- $\mathrm{C}: \mathrm{H}$ formation, as well as the structure and properties of the films.

\section{Experimental}

The ta-C:H films were deposited on $\mathrm{Ti}$ substrates using a cathodic vacuum arc ion plating apparatus (Multi-Arc M500, Nissin Electric, Kyoto, Japan) as shown in Figure 1. Highly purified $(99.99 \%)$ graphite was used as the solid target. The hydrogen content was controlled by setting the $\mathrm{CH}_{4}$ gas flow rate to $0,5,8$, and $11 \mathrm{sccm}$ and fixing the Ar gas flow rate at $30 \mathrm{sccm}$. The total gas pressure was $0.2 \mathrm{~Pa}$. A negative DC bias voltage $(-50 \mathrm{~V})$ was applied to the rotary substrate holder to secure the uniformity of coating. The cathode current was set to $30 \mathrm{~A}$. The deposition time was 43 min.

Pure Ti plates (JIS H4600 TP340 Class 2) with superior biocompatibility, corrosion resistance, 


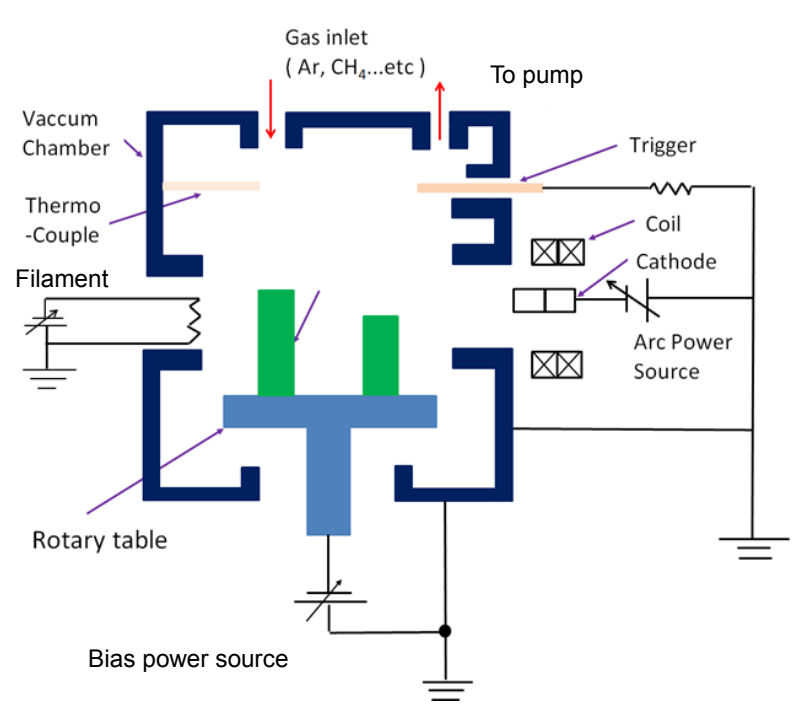

Fig.1 Cathodic vacuum arc ion plating apparatus.

and mechanical properties were used as dental implant substrates. The Ti plate surface $(\varphi 15 \mathrm{~mm} \times$ t1.5 mm) was polished by mechanical polishing using \#600 abrasive papers and chemical polishing. The bias current and voltage, and cathode current and voltage were measured every six seconds using current and voltage meter included in the apertures during film formation.

Hydrogen content was determined using a high-resolution elastic recoil detection analysis (ERDA) made by Kobe Steel, Ltd. The incident energy for $\mathrm{N}^{+}$was $480 \mathrm{keV}$. Film hardness was measured by Nanoindentation (TI-950 Triboindenter, Hysitron) using Berkovich type diamond indenter, with the maximum indentation load of $1000 \mu \mathrm{N}$, and the loading-time, holding-time, and unloading-time of $2 \mathrm{~s}, 5 \mathrm{~s}$, and 2 $\mathrm{s}$, respectively. Three data points were averaged. The structure of the films was evaluated by Raman spectroscopy (RAMAN 11, Nano photon, Osaka, Japan) using the laser wavelength of $532 \mathrm{~nm}$, the intensity of $1 \mathrm{~mW}$, and the objective lens of the magnification 50 times with NA 0.8 .

\section{Results and discussion}

3.1 Current-Voltage characteristics during ta-C:H coating

Figure 2 shows the $\mathrm{CH}_{4}$ gas flow ratio dependence of the cathode voltage for the ta-C:H films. The cathode voltage decreased linearly from $23 \mathrm{~V}$ to $21 \mathrm{~V}$ with increasing $\mathrm{CH}_{4}$ gas flow ratio. This decrease of cathode voltage is because of the increasing production of $\mathrm{CH}_{\mathrm{x}}$ ions with the increase in $\mathrm{CH}_{4}$ ratio inducing a decrease in the space impedance of the plasma. Figure 3 shows the

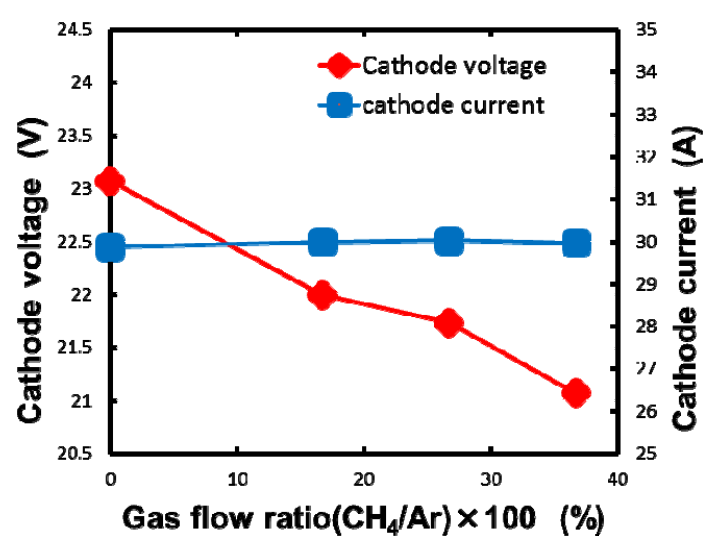

Fig. $2 \mathrm{CH}_{4}$ gas flow ratio dependence of the cathode voltage.

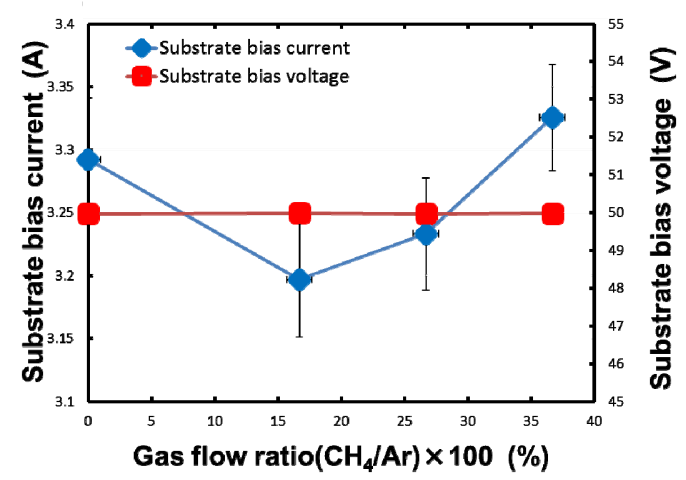

Fig. $3 \mathrm{CH}_{4}$ gas flow ratio dependence of the substrate bias current.

$\mathrm{CH}_{4}$ gas flow ratio dependence of the bias current of the ta-C:H films' substrate. Bias current of the substrate is 3.29 A without the $\mathrm{CH}_{4}$ gas flow. At $\mathrm{CH}_{4}$ gas flow ratio of $16.7 \%\left(\mathrm{CH}_{4}: \mathrm{Ar}=5: 30\right)$, the current decreases to $3.19 \mathrm{~A}$. In contrast, the current increased linearly to $3.33 \mathrm{~A}$ at the $\mathrm{CH}_{4}$ gas flow ratio of $36.7 \%\left(\mathrm{CH}_{4}: \mathrm{Ar}=11: 30\right)$.

The ion produced by the arc discharge that occurred between the cathode and anode is drawn into the substrate by the negative bias voltage. Therefore, we focused on the $\mathrm{CH}_{4}$ flow ratio dependence of the energy conversion efficiency at the cathode current of $30 \mathrm{~A}$ and the bias voltage of $-50 \mathrm{~V}$. The energy conversion efficiency was defined by the following formula (1).

Energy conversion efficiency: $\eta[\%]$

$=$ Bias Power $[\mathrm{W}] /$ Cathode Power $[\mathrm{W}]$

The result is shown in Fig. 4. The energy conversion efficiency $\eta$ is $23.7 \%$ without $\mathrm{CH}_{4}$ gas 
flow, and then increases linearly to $26.3 \%$ with increasing $\mathrm{CH}_{4}$ gas flow ratio. This suggests that the ion generation efficiency of ta- $\mathrm{C}: \mathrm{H}$ process supported by $\mathrm{CH}_{4}$ plasma is higher than that of the ta-C process. Therefore, we can expect improvement of the film formation efficiency including the formation rate, film density, particle density, and resistance in the temperature rise of the substrate.

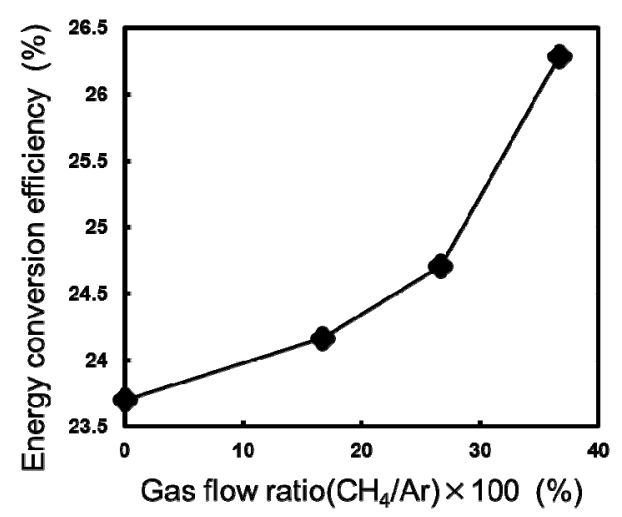

Fig. $4 \mathrm{CH}_{4}$ gas flow ratio dependence of the energy conversion efficiency at the cathode current of $30 \mathrm{~A}$ and the bias voltage of $-50 \mathrm{~V}$.

\subsection{Changing of film properties}

Figure 5 and 6 show the dependence of the hydrogen content and film hardness on the $\mathrm{CH}_{4}$ gas flow ratio for the ta-C:H films as measured by ERDA and Nanoindentor, respectively. The hydrogen content changed linearly from 4 at. $\%$ to 16 at.\% because of changes in the gas flow ratio of $\mathrm{CH}_{4} / \mathrm{Ar}$. Because the hydrogen content changes in the same way as the bias current shown in Figure 3, a strong correlation between these quantities is present for ta-C:H films. The hardness of the ta-C:H film prepared without $\mathrm{CH}_{4}$ gas flow is 57.3 $\mathrm{GPa}$, while that of the ta- $\mathrm{C}: \mathrm{H}$ film prepared with $\mathrm{CH}_{4}$ gas flow of $36.7 \%$ reaches the minimum value of $48.3 \mathrm{GPa}$ that is only $9 \mathrm{GPa}$ lower than the hardness of the film prepared without the $\mathrm{CH}_{4}$ flow. This confirmed that the hardness is only weakly influenced by the $\mathrm{CH}_{4}$ flow ratio.

As shown in Figure 2, the increase of the substrate current with $\mathrm{CH}_{4}$ flow ratio improves the film properties such as film density and hardness.

3.3 Relationship between film structure and Current-Voltage characteristics during ta-C:H coating

Raman spectra show that two peaks at

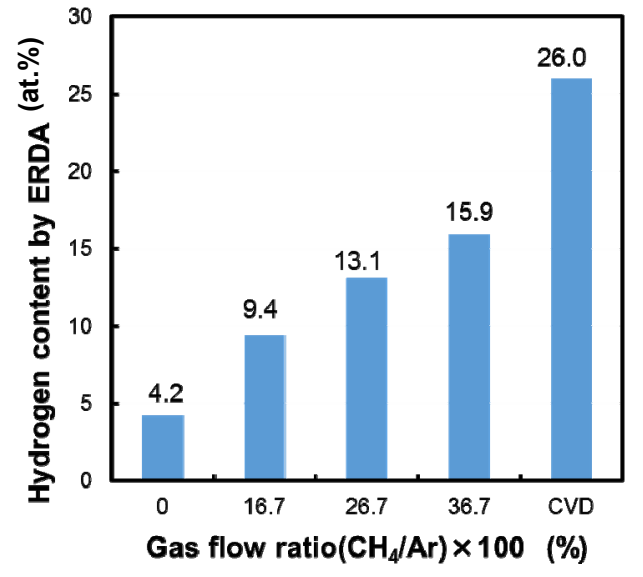

Fig. 5. $\mathrm{CH}_{4}$ gas flow ratio dependence of hydrogen content.

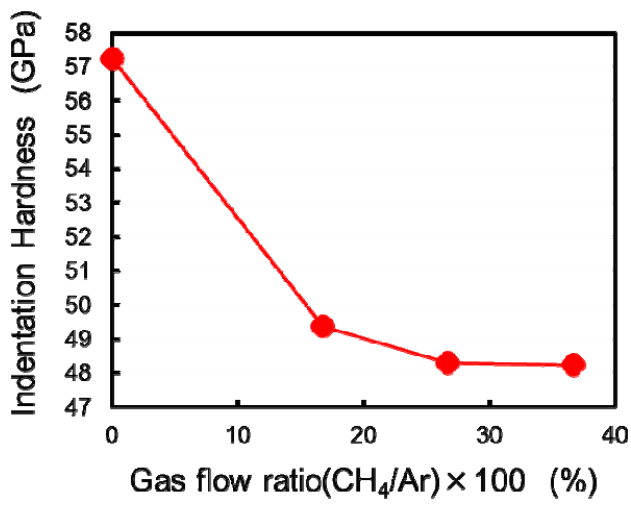

Fig. 6. $\mathrm{CH}_{4}$ gas flow ratio dependence of the indentation hardness.

frequencies of $1350 \mathrm{~cm}^{-1}$ and $1570 \mathrm{~cm}^{-1}$ were observed, corresponding to the D-band and G-band, respectively. ID/IG ratio was calculated by fitting the peak shapes with Gaussian functions. Relationship between the ID/IG ratio and the $\mathrm{CH}_{4}$ gas flow ratio is shown in Figure 7. ID/IG ratio increased from 0.51 to 0.57 at $\mathrm{CH}_{4}$ gas flow ratio of $16.7 \%\left(\mathrm{CH}_{4}: \mathrm{Ar}=5: 30\right)$. An increase of the $\mathrm{CH}_{4}$ gas flow ratio leads to a decrease of the ID/IG ratio to 0.47 at the $\mathrm{CH}_{4}$ gas flow ratio of $36.7 \%\left(\mathrm{CH}_{4}: \mathrm{Ar}\right.$ $=11: 30$ ).

G-Peak position shifts from $1561 \mathrm{~cm}^{-1}$ to 1550 $\mathrm{cm}^{-1}$ at the higher $\mathrm{CH}_{4}$ flow ratio. Ferrari found a strong connection between ID/IG ratio and $\mathrm{sp}^{3}$ carbon bonds (as in diamond) $/ \mathrm{sp}^{2}$ carbon bonds (as in graphite), and reported that the $\mathrm{sp}^{3}$ fraction increased with decreasing ID/IG ratio and G-position [7]. Therefore, it is considered that $\mathrm{sp}^{3}$-bond content increases and $\mathrm{sp}^{2}$-bond content decreases simultaneously because the ID/IG ratio of the ta-C:H films prepared using $\mathrm{CH}_{4}$ gas tends 
to decrease with increasing $\mathrm{CH}_{4}$ gas flow ratio. High hardness of $48.3 \mathrm{GPa}$ was maintained to increase the $\mathrm{sp}^{3}$ contribution even at the higher hydrogen content.

Furthermore, it is found that there was a strong connection between the ID/IG ratio and substrate bias voltage, with the $\mathrm{ID} / \mathrm{IG}$ ratio tending to decrease with increasing substrate bias voltage.

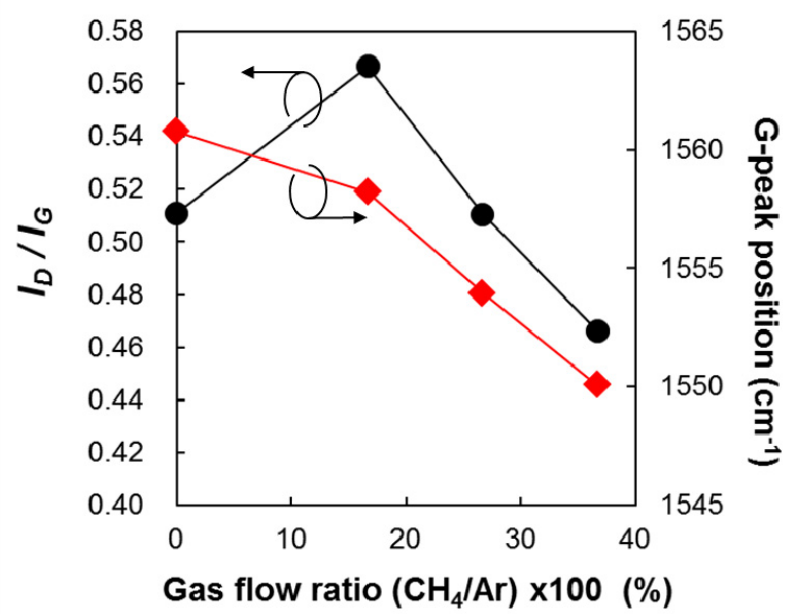

Fig. 7. $\mathrm{CH}_{4}$ gas flow dependence of ID/IG and G-peak Position.

\section{Conclusion}

The purpose of this study is to improve the durability and bone-compatibility of DLC films for use in dental implants. We fabricated ta-C:H films on Ti plates by $\mathrm{CA}$ method using a graphite solid and a $\mathrm{CH}_{4}$ gas as a source for the DLC film, and investigated the $\mathrm{CH}_{4}$ gas flow ratio dependence of the current-voltage characteristics, film properties, and film structures during the ta-C:H formation. It was found that an increase in production of $\mathrm{CH}_{\mathrm{x}}$ ions leads to a decrease in the space impedance of the plasma with increasing $\mathrm{CH}_{4}$ gas flow, and to an increased substrate bias current.

The ta-C:H films avoided hardness lowering and maintained the hardness of $48 \mathrm{GPa}$ even for hydrogen content of 15.9 at.\%. The ta-C:H film fabricated by the CA method was found to be much harder than the a-C:H film fabricated by the CVD method. Therefore, we can expect that ta-C:H films will exhibit good durability and improve the surface of the bone/dental implant. ID/IG ratio measured by Raman spectroscopy tended to decrease with increasing substrate bias voltage.

\section{References}

1) C. Minkin, V. C. Marinho, Adv. Dent. Res., 13 (1999) 49.

2) B. D. Boyan, C. H. Lohmann, D. D. Dean, V. L. Sylvia, D. L. Cochran, Z. Schwartz, Annu. Rev. Mater. Res., 31 (2001) 357

3) G. Avila, K. Misch, P. Galindo-Moreno, H. L. Wang, Implant. Dent., 18 (2009) 17.

4) Y. Mine, T. Nakatani, K. Okamoto, S. Hara, K. Takagi, H. Nikawa, J. Photopolym. Sci. Technol., 27 (2014).

5) K. Okamoto, T. Nakatani, Y. Nitta, $J$. Photopolym. Sci. Technol., 23 (2010) 591.

6) Y. Mine, T. Nakatani, K. Okamoto, S. Makihara, S. Iwata. H. Nikawa, $J$. Photopolym. Sci. Technol., 25 (2012) 523.

7) A. C. Ferrari, Surf. Coat. Thechnol., 180-181 (2004) 190. 